\title{
Increment of Fault Current due to integration of Distributed Generation and its impact on Distribution Network Protection
}

Haymanot Takele Mekonnen ( $\nabla$ haymanot_takele@dmu.edu.et )

Debre Markos University

Original article

Keywords: Fault current level, Distribution system, Protection of Power System

Posted Date: November 9th, 2021

DOl: https://doi.org/10.21203/rs.3.rs-968650/v1

License: (c) (1) This work is licensed under a Creative Commons Attribution 4.0 International License.

Read Full License 


\title{
Increment of Fault Current due to integration of Distributed Generation and its impact on Distribution Network protection \\ Haymanot Takele
}

School of Electrical and Computer Engineering, Debre Markos Institute of Technology, De-

bre Markos University, Debre Markos, Ethiopia, haymanot_takele@dmu.edu.et, $\underline{12 h a y-}$ manot@gmail.com

\begin{abstract}
Background

One of the new technologies in generating power near the distribution system is called distributed generation which has supportive and destructive characteristics to the power system protection. One of the destructive characteristics of distributed generation is increasing the level of fault current to the protective equipment of the power system. In addition to increment of fault, it also alters the radial nature of the power distribution system and cause the power bidirectional rather than unidirectional. Integration of distributed generation to the distribution network causes increment of fault current effect, reliability drop, and affects security of protection system. The level of failure of protection be contingent on type, size, location and number of distributed generation. This fault current can cause a great damage to the electrical equipment with the miss operations of protective devices. The main aim of this paper is analysis of the fault current level to the protection of distribution network due to the integration of distributed generation which concerns on solar distributed generation, wind distributed generation and combination of solar and wind distributed generations at a time. This paper conducts the analysis for the increment of fault current by the integration of distributed generation and its impact on distribution network protection.
\end{abstract}

\section{Results}

The analysis and the modeling are conducted on the $15 \mathrm{KV}$ distribution network of the radial feeder in Debre Markos town. This paper has covered the ling to ground, line to line and three phase fault analysis and their impact on the protection of distribution system for the wind and solar distributed generation types. After the integration of the distributed generation the fault current is increased by $0.529 \mathrm{KA}$ for three phase, $0.74 \mathrm{KA}$ for line to ground, $0.467 \mathrm{KA}$ for line to line and $0.523 \mathrm{KA}$ for line to line to ground.

\section{Conclusions}

This paper confirms designing distribution network without forecasting the future demand of electric power users give the protection equipment additional requirement. As the result, the fault current after the integration of distributed generation to the distribution network have great value in terms of power system protection.

Keywords: Fault current level, Distribution system, Protection of Power System 


\section{Introduction}

Integration of distributed generation (DG) into distribution network (DN) in a radial distribution system (DS) has positive and adverse impacts to the power system[1]. Electrical power system needs plenty of protection mechanism to feed the requirement of the demand by having good reliability performance indices, best security level of supply, minimized harmonics effect, and better quality of power for power demand at any time. The power system can be classified as generation, transmission, and distribution and it needs warmly protection from any sorts of faults. The faults may come from the aging of equipment, outage of the use of the materials, human error in the system of operation, fault due to trees in transmission and distribution of power system, miss operation of protection device, overcurrent, overvoltage, and addition of DG to the DS without protection coordination of the system and from synchronization problem.

The art and science of protecting the components of power system and people during fault condition is called power system protection. In the absence of detecting fault there are conditions which can give hazard output to the power system and the users. Those situations are the over heating's of power system devices, higher or lower value of system voltages, instability of the power system and the conditions are risky. The operation of electrical apparatus with various levels of voltages are placed in open or enclosed for their safety of their health. Protection is needed for the abnormal conditions that can be necessary for electrical equipment safety and safety of humans [2]. The main objective or role of power system protection is detecting and isolating abnormal conditions. These abnormal conditions are happened in electrical power system that are caused by faults, equipment failure and overloads. In power system protection there are also roles that can be classified as secondary which is the result of primary roles and this can be minimizing equipment damages, personnel safety providing's and maximum continuity of services. Those roles listed above are fulfilled by the designing parameters or criteria of power system protections. Reliability, selectivity, speed of operation and economics are some of the design criterion [3].

Integration of DG to the DN causes increment of fault current effect, reliability drop, and affects security of protection system. The level of failure of protection be contingent on type, size, location and number of DG. This fault current can cause a great damage to the electrical equipment with the miss operations of protective devices. Faults that can be occurring by miss operation of protection device can be change from temporary fault to permanent fault. In addition to this, integration of DG complicates and disturbs the operation of protection arrangement. 
The integration of DG may reason of the overloading of protective equipment from their ratings. Traditional DN does not consider the futurity of the protection system due to its cost nature.

The main aim of this paper is analysis of the fault current level to the protection of distribution network due to the integration of DG to the DN. This paper concerns only two types of DG and their impact on the protection of DN. The two DGs are wind and solar and their combinations (only solar DG, only wind DG and solar and wind DG at a time).

\section{Related works}

In $2011 \mathrm{H}$. Zay and ehroodi et al. reviews the impact of DG on the performance of power system protection (PSP). Penetration of DG in high amount or plenty in numbers have impacts on the operation and protections of power system that are fault current contribution increment and changing load flow direction. DG participation in the energy network leads various difficulties with the relation of incorrect operation of the PSP. There is a conflict between the DG and scheme of protection by the reason typically unexpected increment of short circuit currents, protection system coordination deficiency, line reclosing ineffectiveness after a fault and undesired islanding generator protection interface tripping unfortunately. Integrating DG to the DN results the mal operation by providing fault current flows that were not expected in the time of designing the original or traditional DN. In addition to the other parameters and system prior voltage to the fault, the increment of fault current depends on the numbers of factors such as dissemination, capacity, technology, interface and point of connection of DG [4]. In 2015 B. Bak-Jensen, et al. the central base of this paper is the lack of coordination of protection device handling and determining best protection scheme for the DN with DGs. Performance of protective device and different DG units are investigated by making model using DIgSILENT power factor simulation tool [5].

\section{Fault analysis of distribution network with integrations of DG}

$\mathrm{DN}$ is one of the main part of the electric power system which is characterized by design short circuit capacity with the relation of thermal and mechanical equipment competence and constructions [6].

\subsection{Fault or short circuit}

The event which results unwanted damage on a power system that need to be protected before causing broad damage is called short circuit current [7]. The flow of current in an improper way or path of massive magnitude that can be cause damages of equipment which leads to interruption of power, death or injuries of personals is called fault or short circuit. It is also defined as the abnormal connection of relatively low impedance between two points of different potential. The amount of equipment damage can be determined by the amount or magnitude of fault 
current with its duration or life span of fault. The level of voltage also varies and affects the insulation of equipment at the time or case of increase or equipment start-up failure if the level of voltage is minimum. As this case is happen, it results the neutral potential difference increment [3],[8]. Faults can be series fault or parallel fault types [9].

\section{A. Series faults}

Series faults are faults which can be happen by the causes of:

Failures of cable joints, blown fuses, Failure of breakers to open all poles,

Unintentional breaker energization across one or two poles and their situations that result in the flow of unbalanced currents.

Series faults are fault situations that may be one of the following types of system unbalances:

Two lines open,

One line open or

Unequal impedances which is disturbed line impedance gap.

Series fault types are graphically presented in the figures below:

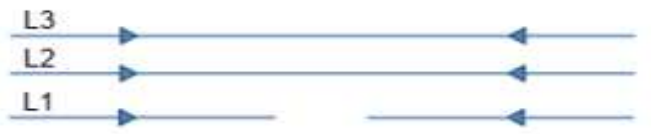

One line open

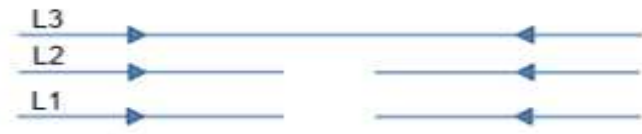

Two lines open

Figure 1 series fault types [10]

\section{B. Parallel or shunt faults}

Parallel or shunt faults are faults which are the contact of two or more conductors with the corresponding ratings. The common types of parallel or shunt faults occur in power system that address one or more of the following four kinds of short circuits [9], [10]:

LL: the connection or contact of one line of conductor to another line of conductor which carries electrical power. It lines contacts may be R\&S, R\&T or ST shorted together.

DLG: this fault type is a fault type which is made by the contacts of two line with a ground line. This contact also may be between RS \& ground, RT \&ground or ST $\&$ ground.

LG: the contact of any of the three lines to the ground is called single line to ground fault.

Three-phase fault: the fault which is occurred by the contact of all the three lines at a time. This fault type may or may not include the ground by its naming. The contact of three lines including ground and without including ground is call by three phase faults.

Fault types are graphically presented in the figures below: 


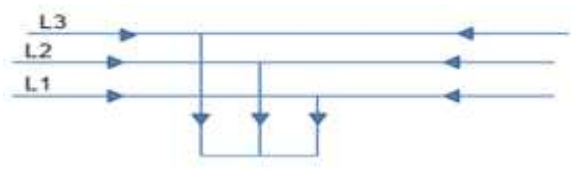

Three Phase Fault

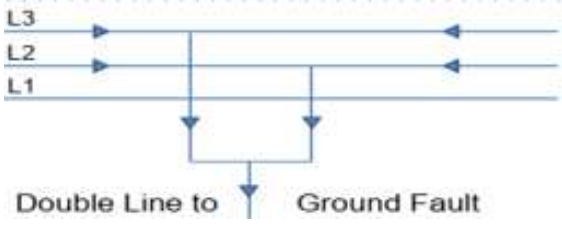

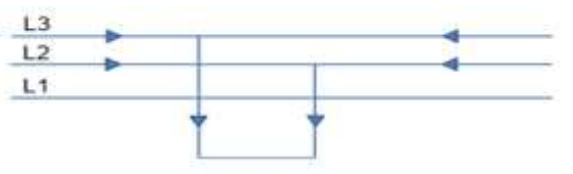

Line to Line Fault

L3

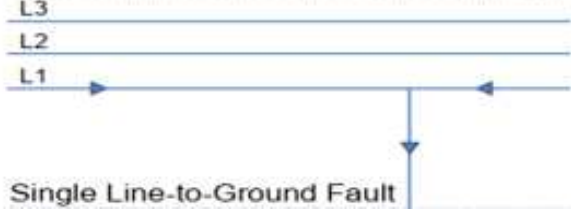

Figure 2 types of faults (parallel)[10]

\section{Statistics of fault based on types of faults}

The following table summarizes the statistics of fault with severity and percentage of occurrence in power system.

Table 1 statistics of fault based on types of faults

\begin{tabular}{|l|l|l|l|}
\hline No. & Fault Type & Occurrence Probability (\%) & Severity \\
\hline 1. & Single Line to Ground (SLG) & 85 & Least \\
\hline 2. & Line-Line (LL) & 8 & \\
\hline 3. & Double Line to Ground (LLG) & 5 & Most \\
\hline 4. & Three Phase Bolted (LLL) & 2 & \\
\hline
\end{tabular}

\subsubsection{Source of fault}

Some of the sources of fault are natural events, physical accidents, failure of equipment and failure to operate correctly.

Table 2 source of fault [11]

\begin{tabular}{|l|l|l|c|}
\hline \multicolumn{5}{|c|}{ Source of faults } \\
\hline Natural sources & Physical events & Failure of equipment & Miss operation \\
\hline$\bullet \quad$ Wind Snow, Ice & $\bullet$ Car accidents & $\bullet$ Insulation failure & \\
$\bullet \quad$ Lightening & $\bullet$ Animal and & & \\
- Falling trees & $\bullet$ human contact & & \\
- Earth quack, & & & \\
- Tornados & & & \\
\hline
\end{tabular}

\subsubsection{IEC 60909 standard overview}

For each of specific location and time of short circuit perspectives in power system IEC 60909 standard derives the maximum and minimum short-circuit currents [7]. The analysis of short circuit current in $50 \mathrm{~Hz}$ or $60 \mathrm{~Hz} 3 \Phi$ ac system is also can be done by using IEC 60909 standard. Nominal voltage of the system with rated values of the equipment is the only way to calculate fault current level [6].

\subsubsection{Short circuit calculation overview}

Accidental contacts in a minimal impedance value between an electrical circuit that may be two or more and operates with potentials differently are represented by short circuit. In the network of electric system short circuit can occur in four different types. These are $3 \Phi$ symmetrical (which have a characteristics of low frequency rate occurrence from $5 \%$ to $10 \%$ and 
used for as the basic element in the studies of electrical network operating and design), phase to phase, phase to phase to ground and phase to ground short circuits [12].

\subsubsection{Components of short circuit}

There are two types of components in a simple $R+j X$ inductive circuit. These components are decaying ac and dc component. By summing these two components the total current can be provided. The detail of the two components is discussed in [7].

\subsection{Fault current calculation}

Fault values of a circuit total resistance and reactance allows to determine fault current of installation to be calculated. Sum of respective network elements are obtained from the total fault reactance and resistance and the equivalent impedance $Z_{T K}$ is expressed as follows [13].

$$
Z_{T K}=\sqrt{R_{T K}^{2}+X_{T K}^{2}}
$$

By using the equivalent impedance, voltage factor " $c$ " and nominal voltage " $U_{n}$ ", a three-phase symmetrical fault current level can be determined. A fault which generates highest current is generally considered as the symmetrical fault level current and given by:

$$
I_{3 \emptyset}=\frac{c U_{n}}{\sqrt{3} * Z_{T K}}
$$

In the absence of rotating machine or having low effect of it, a three-phase symmetrical fault level current value represents steady state current. The breaking capacity of the protection device is determining by this steady state current and it is taken as a reference to determine the breaking capacity of the protection device [13].

\subsection{Fault level calculation in DN with DG}

The level of fault current with the effect of fault is expressed in terms of power or current. This can indicate the increment of power and the fault level in PU is expressed as below. It is the collection of inner impedance of Thevenin equivalent circuit, $\mathrm{z}_{\mathrm{th}}$ and fault current related to the nominal current, i [14], [15].

$$
f_{l}=i=\frac{1}{z_{\text {th }}}
$$

The fault current in a faulted feeder is changed by the connection of DG to the distribution feeder and the fault current rate depends strongly on the DG ability to contribute the fault current [16]. Calculating the fault levels are performed on a $15 \mathrm{KV}$ DS. Since the algebraic sum of short circuit current is contributed from the network such as motor loads, generators and transformers, the initial short circuit, which is three phase symmetrical fault, is calculated by the following equations [17].

\subsubsection{Fault contribution of the main grid and the DG}

When the grid contribution is minimum to the short circuit, reversely the DG contribution to the short circuit is maximum [16]. 


\subsubsection{Fault contribution of the main grid}

Fault contribution of MG is the fault only without the integration of any type of power source and with fault happened to the system (with any type of fault). The fault is happened at bus A and the magnitude of the fault is expressed as equation (4).

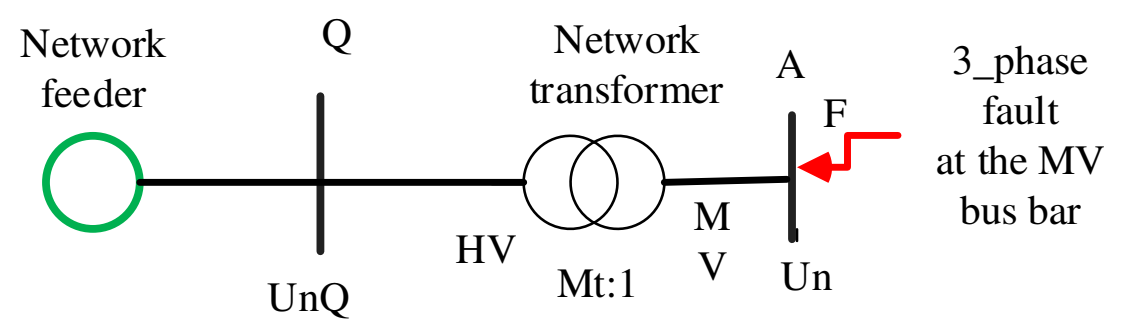

Figure 3 fault contribution of the main grid

For the calculation of the main grid fault level contribution eq. (4) is used.

$$
I_{K}^{\prime \prime}=\frac{c_{\max } U_{n}}{\sqrt{3}\left(Z_{Q}+Z_{L}+Z_{R}+Z_{K T}\right)}
$$

Where, $Z_{Q}$ : main grid impedance at the connection point $\mathrm{Q}, Z_{T}$ : transformer impedance, $Z_{R}$ : series reactor (R) (if any), $K_{T}$ : correction factor, $Z_{L}$ : line impedance

Quantities which are calculated above are obtained by using the following.

$$
\begin{gathered}
Z_{Q}=\frac{c U_{n}}{\sqrt{3} I_{K Q}^{\prime \prime}} \\
Z_{T}=\frac{u_{k r}}{100 \%} * \frac{U_{r T}^{2}}{S_{r T}^{2}} \\
R_{T}=\frac{u_{R r}}{100 \%} * \frac{U_{r T}^{\prime \prime}}{S_{r T}^{2}}=\frac{P_{k r T}}{3 I_{r T}^{2}} \\
K_{T}=0.95 * \frac{c_{\max }}{1+0.6 x_{T}} * \frac{U_{r T}^{2}}{S_{r T}^{2}}, X_{T}=\sqrt{Z_{T}^{2}-R_{T}^{2}}
\end{gathered}
$$

Where symbols $u_{k r}, P_{k r T}$, and $I_{K Q}^{\prime \prime}$ used in the calculations are fault voltage of transformer, load loss at load current and initial symmetrical fault current at the high voltage connection point $\mathrm{Q}$ respectively.

\subsubsection{Fault contribution of DG}

After the integration of DG and fault happened at point a (fault location) near bus B4 the analysis becomes as figure (5). The fault contribution of the grid and the DG is calculated as shown in equation (9).

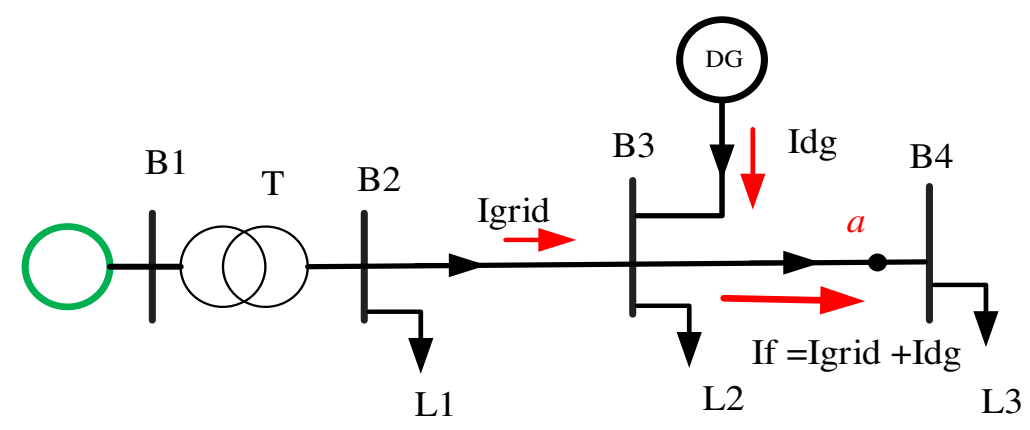


Figure 4 Fault contribution of DG

$$
\begin{gathered}
I_{K}^{\prime \prime}=\frac{c_{\max } U_{n}}{\sqrt{3}\left(Z_{G}+Z_{Q}+Z_{L}+Z_{R}+Z_{K T}\right)} \\
\mathrm{U}_{\mathrm{r}}=\mathrm{I}_{\mathrm{nw}} * \mathrm{Z}_{23}+\left(\mathrm{I}_{\mathrm{nw}}+\mathrm{I}_{\mathrm{DG}}\right) * \mathrm{Z}_{3 \mathrm{a}} \\
\mathrm{Z}_{\mathrm{r}}=\frac{\mathrm{U}_{\mathrm{r}}}{\mathrm{I}_{\mathrm{nw}}}=\mathrm{Z}_{23}+\mathrm{Z}_{3 \mathrm{a}}+\frac{\mathrm{I}_{\mathrm{dg}}}{\mathrm{I}_{\mathrm{nw}}} * \mathrm{Z}_{3 \mathrm{a}}(\text { called disturbance })
\end{gathered}
$$

Where: $\mathrm{Z}_{\mathrm{r}}$ : apparent impedance; $\mathrm{U}_{\mathrm{r}}$ : voltage measured by the relay; $\mathrm{I}_{\mathrm{nw}}$ : grid current; $\mathrm{Z}_{23}$ : line impedance from bus $b_{2}$ to $b_{3} ; I_{d g}$ : DG current contribution; $I_{f}$ : fault current; $Z_{3 a}$ : impedance between $\mathrm{z}_{3}$ and fault location (point a)

\subsection{DG Influence on Protection Scheme of Distribution Network}

Integration of DG have influences on the protections of the DN schemes. These influences are protection blinding, untrue or false tripping, prevention or prohibition of automatic reclosing, reverse power flow and lack of synchronization of automatic reclosing [16],[18].

\subsubsection{Protection blinding}

This is one of the influences of the DG to the protection scheme of the DN. At the event of fault including DG short circuit current is contributed by both the MG and DG and it depends on the configuration of the network, size of the DG and the impedance of the grid. Therefor the influence DG on the protection in protection blinding is described as follows.

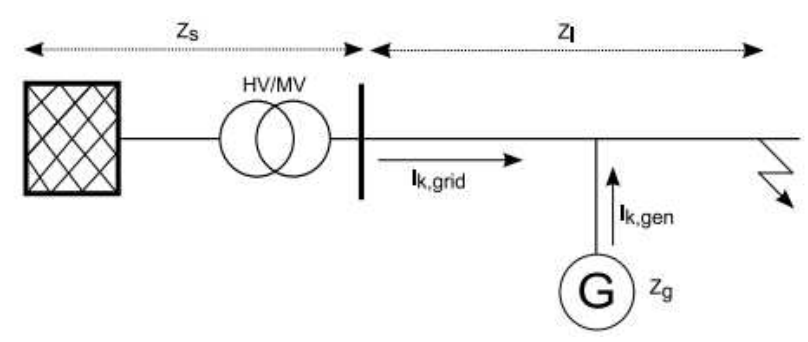

Figure 5 Protection blinding on the DN

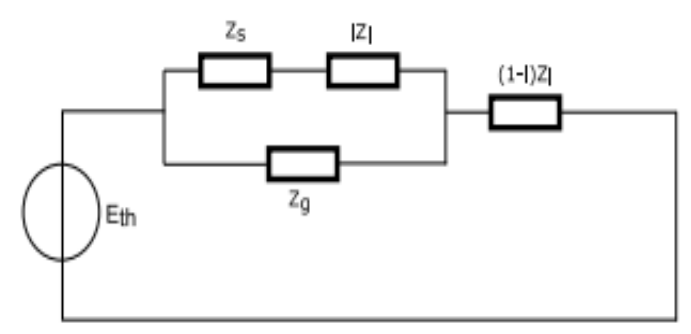

Figure 6 Thevenins equivalent of Figure 6 
The equivalent Thevenins impedance $\mathrm{Z}_{\mathrm{th}}$ is calculated based on figure 7 and it becomes:

$$
\mathrm{Z}_{\mathrm{th}}=\frac{\left(\mathrm{Z}_{\mathrm{s}}+\mathrm{l} * \mathrm{Z}_{\mathrm{t}}\right) \mathrm{Z}_{\mathrm{g}}}{\mathrm{Z}_{\mathrm{s}}+\mathrm{l} * \mathrm{Z}_{\mathrm{l}}+\mathrm{Z}_{\mathrm{g}}}+(1-\mathrm{l}) \mathrm{Z}_{\mathrm{l}}
$$

Where $Z_{s}$ - grid impedance including transformer, $Z_{g}$ - impedance of generator, $Z_{l}-i m$ pedance of the line and $l$ - relative length of the line which is between $0 \& 1$

Calculating the short circuit current in each phase is the next step by using the Thevenins equivalent impedance $Z_{\text {th }}$ and the Thevenins equivalent voltage $U_{\text {th }}$.

$$
\mathrm{I}_{\mathrm{K}, 3 \varphi}=\frac{\mathrm{U}_{\mathrm{th}}}{\sqrt{3} * \mathrm{Z}_{\mathrm{th}}}
$$

The current which is contributed by the grid is also calculated by using grid impedance including transformer $\mathrm{Z}_{\mathrm{s}}$, impedance of generator $\mathrm{Z}_{\mathrm{g}}$, impedance of the line $\mathrm{Z}_{\mathrm{l}}$ and relative length of the line 1 . Therefore, the equation becomes:

$$
\mathrm{I}_{\text {grid }}=\frac{\mathrm{Z}_{\mathrm{g}}}{\left(\mathrm{Z}_{\mathrm{s}}+\mathrm{l} * \mathrm{Z}_{\mathrm{l}}\right)+\mathrm{Z}_{\mathrm{g}}} * \mathrm{I}_{\mathrm{K}, 3 \varphi}=\frac{\mathrm{Z}_{\mathrm{g}}}{\left(\mathrm{Z}_{\mathrm{s}}+\mathrm{l} * \mathrm{Z}_{\mathrm{l}}\right)+\mathrm{Z}_{\mathrm{g}}} * \frac{\mathrm{U}_{\mathrm{th}}}{\sqrt{3} * \mathrm{Z}_{\mathrm{th}}}
$$

$\mathrm{Z}_{\mathrm{s}}$ is determined by local short circuit power $\mathrm{S}_{\mathrm{k}}{ }^{\prime \prime}$ of the main grid transmission. Having the ideal case as $\mathrm{S}_{\mathrm{k}}{ }^{\prime \prime} \rightarrow \infty=>\mathrm{Z}_{\mathrm{s}} \rightarrow 0$ then

$$
\mathrm{I}_{\text {grid }}=\lim _{\mathrm{Z}_{\mathrm{s}} \rightarrow 0} \frac{\mathrm{Z}_{\mathrm{g}}}{\left(\mathrm{Z}_{\mathrm{s}}+\mathrm{l} * \mathrm{Z}_{\mathrm{l}}\right)+\mathrm{Z}_{\mathrm{g}}} * \mathrm{I}_{\mathrm{K} \infty}=\frac{\mathrm{Z}_{\mathrm{g}}}{\left(\mathrm{l} * \mathrm{Z}_{\mathrm{l}}\right)+\mathrm{Z}_{\mathrm{g}}} * \mathrm{I}_{\mathrm{K} \infty}=\frac{1}{\frac{\mathrm{l} * \mathrm{Z}_{\mathrm{l}}}{\mathrm{Z}_{\mathrm{g}}}+1} * \mathrm{I}_{\mathrm{K} \infty}
$$

This indicates that the location and size of generator in the feeder the short circuit current con-

tribution of the grid. When the value of the $\frac{1 * Z_{1}}{Z_{g}}$ is small then $I_{\text {grid }} \approx I_{K \infty}$ this is because of smaller length or smaller capacity of the installed generator which have larger $\mathrm{Z}_{\mathrm{g}} . \mathrm{S}_{\mathrm{k}}{ }^{\prime \prime} \rightarrow \infty$ is never happened at the real world and equation (14) no longer holds and specially $\mathrm{S}_{\mathrm{k}}{ }^{\prime \prime}$ in MV grid can have low value this leads the non-negligence of the impedance. Therefore, effect of DG on short circuit current contribution on the main grid can be explained in equation (12). Equations (13) \& (14) are not linear with location and size of DG and also $\mathrm{I}_{\text {grid }}$ is not linear then the total short circuit current determined by equations (12) \& (13). Due to the week grid $\mathrm{Z}_{\mathrm{s}}$ and $\mathrm{Z}_{\mathrm{g}}$ are large and short circuit contribution of the grid decreases and the short circuit stays with no detection by the low grid contribution of short circuit and it is unable to reach to the pickup current of the feeder relay. The above explanation is called blinding of protections [18].

\subsubsection{False tripping}

This is the process in which the disconnection of healthy feeder because of the influence of DG to the main grid of the adjacent feeder and the exceeding of the pickup current of the protection overcurrent due to the contribution of DG leads to trip the healthy feeder before the time of trip 
to the actual fault clearance. This can happen when the DG and the fault location is near substation [18] .

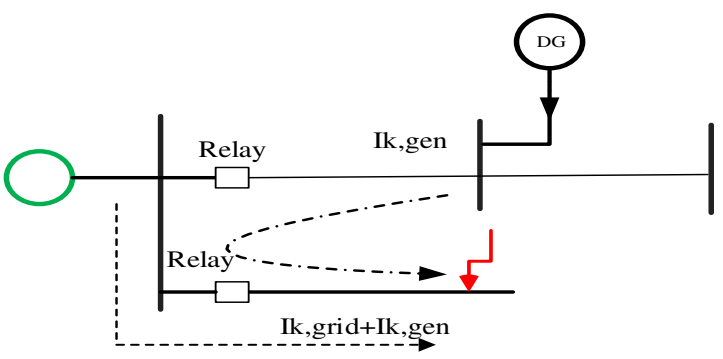

Figure 7 false tripping principle

\subsubsection{Loss of coordination}

When the level of fault increases in the network, the coordination of protective devices could be losing. The increment of short circuit level leads to the relay to be operate in shorter interval and also this consequence is losing of coordination of margin between primary and backup relays.

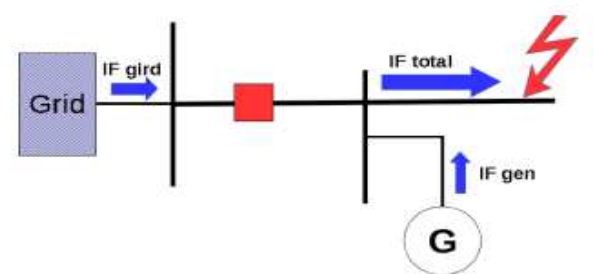

Figure 8 Principle of loss of Coordination

\section{Protection of DG and DN}

\subsection{Power system protection}

In electrical power system there are three main processes. These processes are production, transmission and distribution of electrical power to the demand. Making these processes as safe as possible from the effect of failure and preventing the power system from risk is called power system protection. The power system protection goals are public safety, equipment protection and power system integrity [19].

The popularity of DG is increased due to increment of demand for energy and its emphasis of clean energy. Power system has a nature of radially flow which the power flows from the generation to the power demand. The integration of DG to the network it alters the radial nature to bidirectional flow of power. Bidirectional power flow is the flow of power in two opposite directions. So, the power flows from DG to the main grid, main grid to DG as well as load to both the main grid and DG. The flow of power in a bidirectional way causes complications in power quality, power flow control, energy management, voltage profile, frequency control, adequacy, security and protection. There are different problems that DG causes. These causes 
are protection device losing, feeders' false trip, generators false trip, short circuit level increment and decrement and blinding of protection. Protection coordination depends on the capacity, type and location of the DG.

The criterion that the power system protection which are fundamentals of protection coordination must have satisfied the following five. These are reliability, selectivity, speed, simplicity and economics. The detail of these lists are as below [3],[20], [21].

\section{A. Reliability}

The level of dependability and security depends on the high reliability of protection system. The reliability of the protective equipment (relays) have a percentage value above $99 \%$ and this indicates the device have good characteristics which is operate correctly with less malfunctioning.

\section{B. Selectivity}

As the name indicates the protective equipment must have the ability to select the faulty section to unfaulty for the purpose of disconnecting the system that have a problem that leads the overall system unhealthy. The protective devices must be protecting both the highest short circuit current $\mathrm{I}_{\mathrm{fmax}}$ and the lowest short circuit current $\mathrm{I}_{\mathrm{fmin}}$.

\section{Speed of operation}

For the purpose of adequate protection isolation of the affected section of the power system is mandatory and if the protective devices are speedy to isolate the affected section it is used to minimize the short current magnitude and it leads less equipment damage. The rate of damage to electrical equipment with risk to personnel is depends on the flow of fault current durations. Power system protection equipment must operate as fast as possible without stability compromising [21],[22].

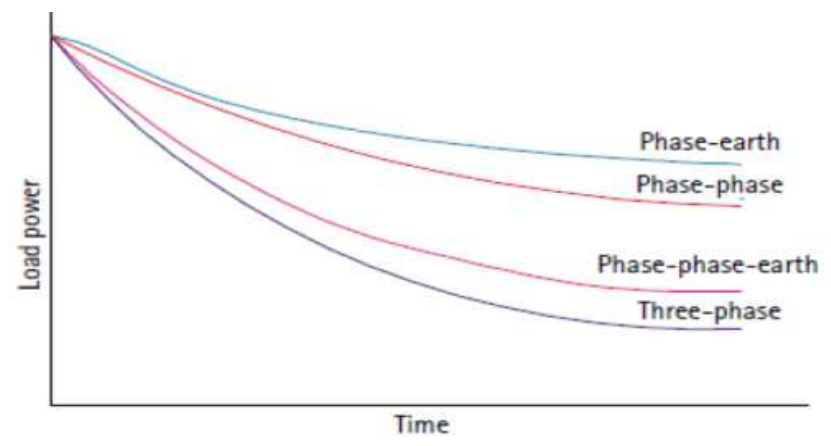

Figure 9 Time relationship for various fault types

\section{Simplicity}


In electrical power system there are different types of components inside the system. From those components protective device is the one. When the protective device is designed by engineers it must be in a minimum protective equipment and associate circuit to achieve the level of protection.

\section{E. Economics}

One of the constraints of designing equipment is its cost. The design is said to be good design when it fulfills the coordination of good protection and less cost.

\subsection{Grid connected DG protection}

Integration growing of DG into the DN requests the approach of traditional protection system and theories. When DG is integrated to the DN, it changes from passive network to active network since it gets generated power to it's near. This leads coordination problems of circuit breaker, fuses and reclozer and also changes the direction and magnitude of fault current that causes the coordination problem. The influence of DG depends on the penetration level, type of DG and interfacing device type (i.e. power electronics devices or synchronous machine) [23].

\section{Result and Discussion}

Integration of DG into existing DN have adverse impact on increasing level of fault current to the protective devices installed in the system. This increased level of fault current causes protective device blind, tripping without its scheduled time or coordinating time interval, and needs to be replace the protective device by another. In this paper section there are different sorts of scenarios to be studied. From those scenarios base case fault current level analysis result, impact on fault current level with two selected DG types are discussed.

\subsection{Scenario I: Base-case fault current level}

The base case fault current calculation is shown in figure 11 which is calculated without the integration of DG to the system and considering all the 62 buses as fault location turn by turn. This helps to know the impact of DG in the DN protection to the fault level by distance of the fault location in the integration of DG. The maximum and minimum fault current level of 3_phase fault in KA is 0.860 and 0.613 respectively. The protective device for the base case is designed based on the maximum fault happen to the DN. The fault current level can mitigate only by the designed protective devices installed and the system does not need additional equipment's to protect fault from damaging the electrical devices. 


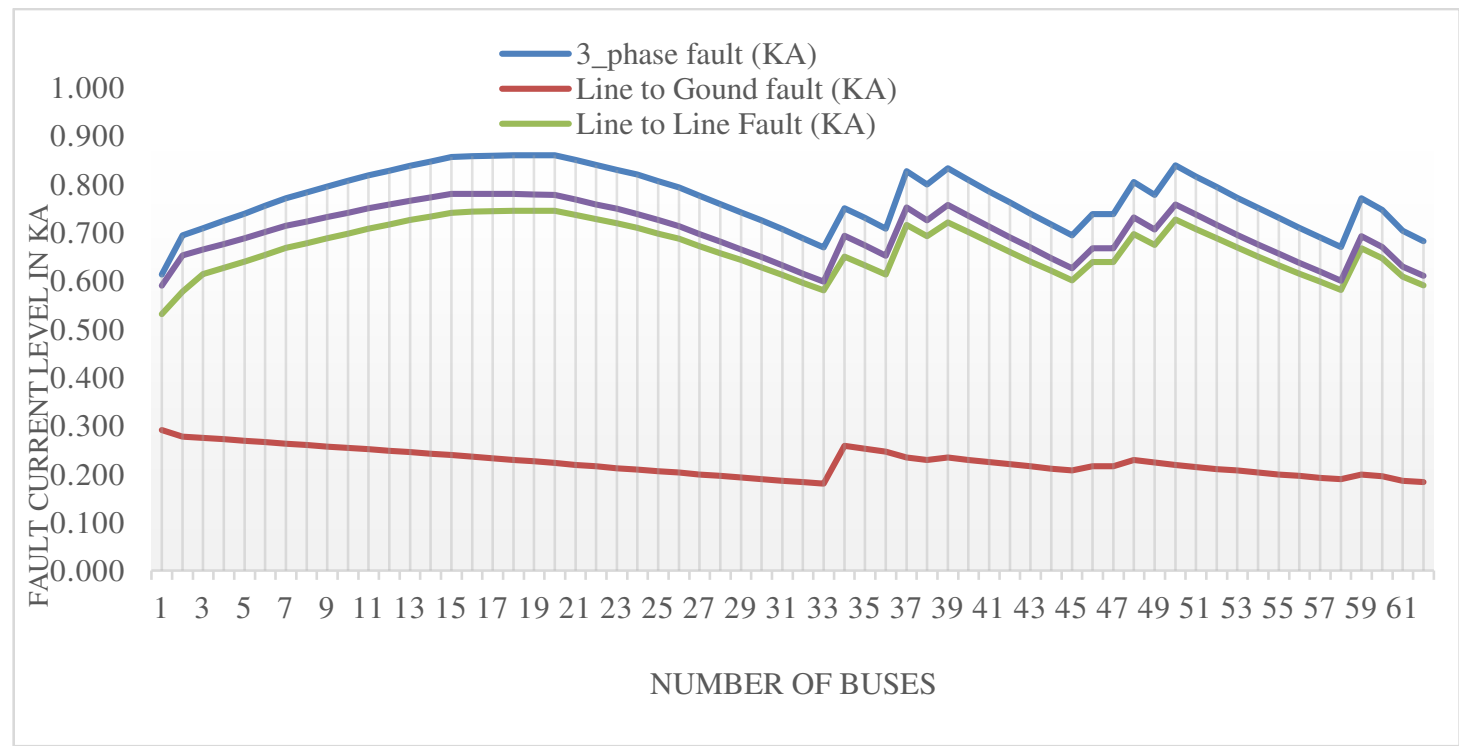

Figure 10 Base case fault current level analysis for the 62 buses DN

The severity ranks of the faults starting from one to four are three phase (with 0.613KA minimum and 0.860KA maximum), DLG fault (with minimum 0.590KA and maximum 0.780KA), LL fault (with minimum $0.531 \mathrm{KA}$ and maximum $0.745 \mathrm{KA}$ ) and SLG (with minimum $0.180 \mathrm{KA}$ and maximum $0.291 \mathrm{KA}$ ). This indicates that the theoretical and simulation result are correctly related and it shows a good result for the base case study.

\subsection{Scenario II: Fault current levels for the selected weak buses}

By using loss sensitivity factor this research work identifies four weak buses. These buses are bus 31 , bus 32 , bus 33 and bus 62 as indicated in figure 12 of the voltage profile.

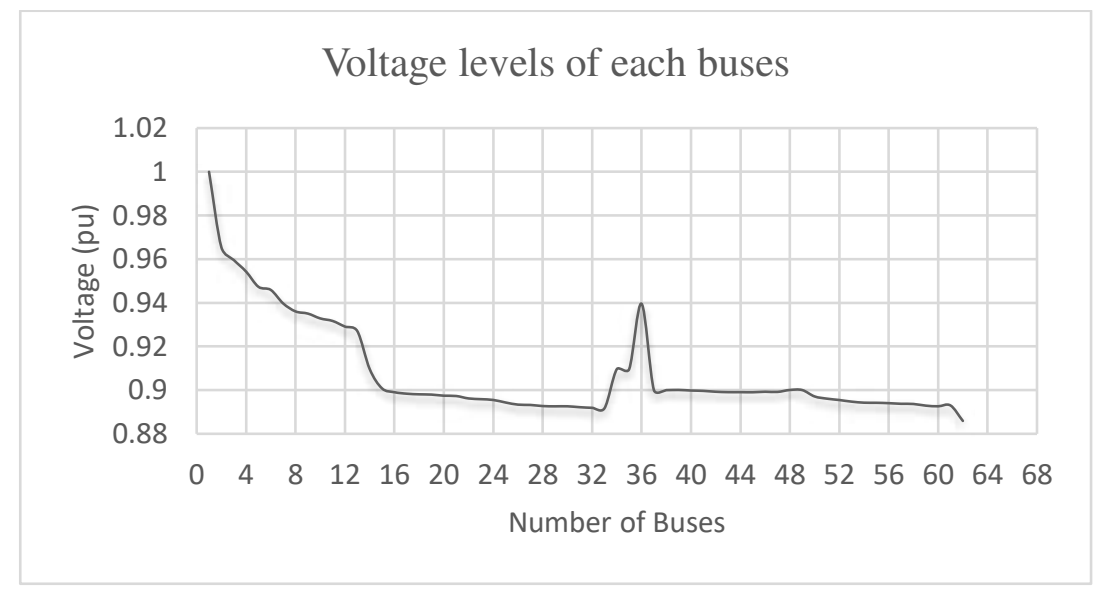

Figure 11 Base case voltage profile (pu) of the 62 bus DN

The selected buses are used for the placement of DG and analysis of fault level to know adverse impact of DG. DG have great impact to increase fault current level to the DN are type of DG (solar and wind), location of DG (4 selected weak buses these are bus 31, bus 32, bus 33 and bus 62), number of DG (two which are wind DG and solar DG located at a time and individually) and distance from the fault location. To analyze those effects for how much level that the 
above listed cases are affected the level of the fault current, this paper has done arrangements which are applying the integration of DG with the selected bus numbers one DG type at a time for solar and wind DG and the two DG types at a time in each selected weak bus. This is done after sizing the optimal DG by using PSO and identifying the weak bus by loss sensitivity factor. The adverse impact of DG is analyzed in optimal size and placement of DG to show how the integration of DG can affects the protection of the DN and how much it increases the fault current level to the traditionally sized DN protection system.

The voltage profile for the weakest bus is located at bus 62 with a value of $0.8859 \mathrm{pu}$. The other weak buses are bus 31 with a voltage profile of $0.8922 \mathrm{pu}$, bus 32 with a voltage profile of $0.8918 \mathrm{pu}$ and bus 33 with a voltage profile of $0.8917 \mathrm{pu}$. The PSO is used for knowing the optimal size and place of the DG applied for this paper to do a fault analysis and print out the fault current level for both the base case and the study case after the integration of DG in each weak bus and the optimal location of DG.

\section{Solar DG}

Solar DG is placed at four locations which are bus 31, bus 32, bus 33 and bus 62 turn by turn and the result of fault analysis is recorded in table 3 below.

Table 3 Solar DG and types of faults

\begin{tabular}{|c|c|c|c|c|c|c|c|c|}
\hline \multirow{2}{*}{ FL } & \multicolumn{5}{|c|}{ 3_phase (KA) } & \multicolumn{4}{c|}{ LG (KA) } \\
\cline { 2 - 9 } & Bus 31 & Bus 32 & Bus 33 & Bus 62 & Bus 31 & Bus 32 & Bus 33 & Bus 62 \\
\hline 31 & 0.786 & 0.793 & 0.779 & 0.800 & 0.215 & 0.217 & 0.213 & 0.234 \\
\hline 32 & 0.765 & 0.772 & 0.758 & 0.779 & 0.212 & 0.214 & 0.210 & 0.231 \\
\hline 33 & 0.745 & 0.752 & 0.738 & 0.758 & 0.208 & 0.209 & 0.206 & 0.227 \\
\hline 62 & 0.758 & 0.765 & 0.751 & 0.772 & 0.211 & 0.213 & 0.209 & 0.230 \\
\hline FL & & \multicolumn{2}{|c|}{ LL (KA) } & & & DLG (KA) & \\
\cline { 2 - 10 } & Bus 31 & Bus 32 & Bus 33 & Bus 62 & Bus 31 & Bus 32 & Bus 33 & Bus 62 \\
\hline 31 & 0.680 & 0.687 & 0.674 & 0.693 & 0.707 & 0.713 & 0.701 & 0.720 \\
\hline 32 & 0.663 & 0.669 & 0.657 & 0.675 & 0.687 & 0.693 & 0.681 & 0.699 \\
\hline 33 & 0.645 & 0.651 & 0.639 & 0.657 & 0.668 & 0.674 & 0.662 & 0.680 \\
\hline 62 & 0.657 & 0.663 & 0.651 & 0.669 & 0.682 & 0.688 & 0.675 & 0.694 \\
\hline
\end{tabular}

The above table indicates that varying the location of DG and fault location increases the level of fault current. The following graph shows the bar graph of the above table.

\section{Wind DG}


In this scenario the fault analysis is done on the four fault locations only and the other faulty location is recorded on the appendix table. This is for showing the impact of solar DG to the DN fault level contribution. As fault location is near to the DG location the level of short circuit current increases. Table 4 shows the three phase, line to ground (LG), line to line (LL) and double line to ground (DLG) fault with the fault locations (FL) of bus 31, bus 32, bus 33 and bus 62 .

Table 4 3Ф fault analysis of selected weak buses with maximum and minimum values

\begin{tabular}{|c|c|c|c|c|c|c|c|c|c|}
\hline \multirow{2}{*}{ FL } & \multicolumn{5}{|c|}{ 3_phase (KA) } & \multicolumn{5}{c|}{ LG (KA) } \\
\cline { 2 - 11 } & Bus31 & Bus 32 & Bus 33 & Bus 62 & Bus 31 & Bus 32 & Bus 33 & Bus 62 \\
\hline 31 & 1.247 & 1.235 & 1.223 & 1.191 & 0.937 & 0.889 & 0.847 & 0.793 \\
\hline 32 & 1.192 & 1.229 & 1.217 & 1.140 & 0.864 & 0.930 & 0.883 & 0.740 \\
\hline 33 & 1.140 & 1.174 & 1.210 & 1.091 & 0.800 & 0.857 & 0.922 & 0.692 \\
\hline 62 & 1.137 & 1.127 & 1.118 & 1.223 & 0.768 & 0.736 & 0.708 & 0.928 \\
\hline FL & \multicolumn{7}{|c|}{ LL (KA) } & & \multicolumn{7}{c|}{ DLG (KA) } \\
\cline { 2 - 12 } & Bus 31 & Bus 32 & Bus 33 & Bus 62 & Bus 31 & Bus 32 & Bus 33 & Bus 62 \\
\hline 31 & 1.089 & 1.078 & 1.068 & 1.039 & 1.157 & 1.135 & 1.117 & 1.084 \\
\hline 32 & 1.040 & 1.073 & 1.063 & 0.994 & 1.103 & 1.143 & 1.122 & 1.039 \\
\hline 33 & 0.994 & 1.025 & 1.057 & 0.951 & 1.054 & 1.090 & 1.129 & 0.996 \\
\hline 62 & 0.992 & 0.983 & 0.974 & 1.068 & 1.044 & 1.029 & 1.016 & 1.139 \\
\hline
\end{tabular}

\section{Solar and Wind DG}

After the integration of solar and wind DG at the four weak buses which are bus 31 , bus 32 , bus 32 and bus 62 for knowing the contribution fault current of DG and the DS in each weak buses plotted as figure 15. The fault location with a fixed DG placement have various magnitude of fault current level.

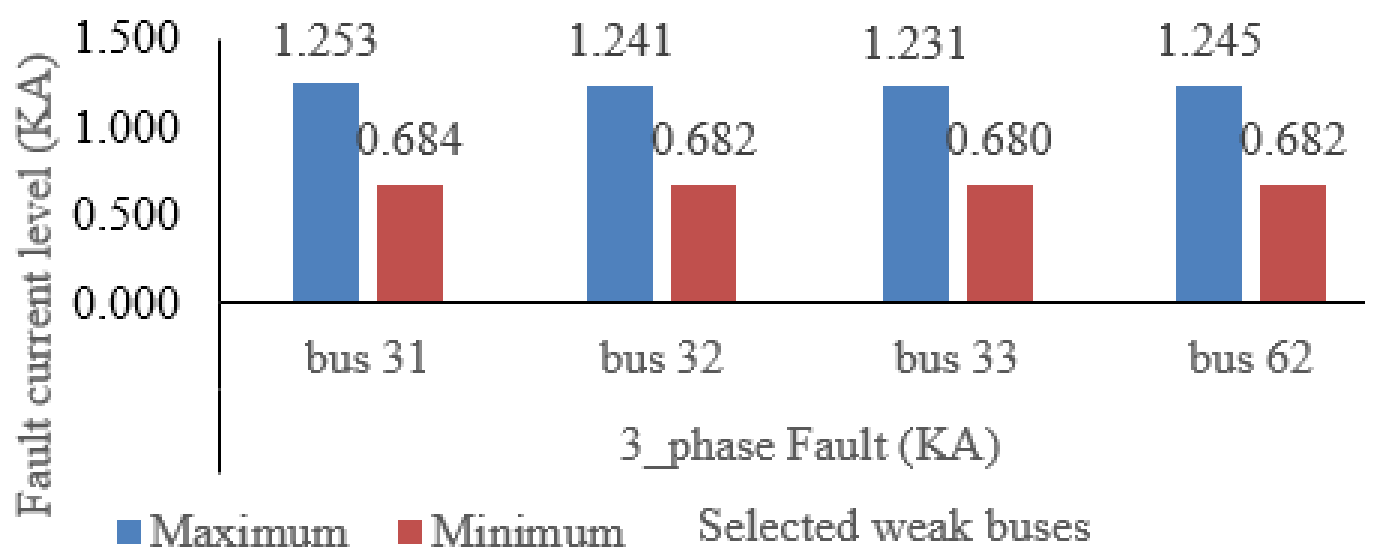

Figure $123 \Phi$ fault analysis of selected weak buses with maximum and minimum values 
From the fault locations selected the weakest buses are listed shown in table 5 below with the fault current level.

Table 5 Solar and wind DG and types of fault

\begin{tabular}{|c|c|c|c|c|c|c|c|c|}
\hline & \multicolumn{4}{|c|}{ 3_phase (KA) } & \multicolumn{4}{|c|}{ LG (KA) } \\
\hline FL & Bus 31 & Bus 32 & Bus 33 & Bus 62 & Bus 31 & Bus 32 & Bus 33 & Bus 62 \\
\hline 31 & 1.236 & 1.224 & 1.212 & 1.178 & 0.933 & 0.886 & 0.844 & 0.789 \\
\hline 32 & 1.179 & 1.217 & 1.205 & 1.125 & 0.859 & 0.926 & 0.879 & 0.735 \\
\hline 33 & 1.125 & 1.160 & 1.198 & 1.075 & 0.795 & 0.977 & 0.918 & 0.687 \\
\hline \multirow[t]{2}{*}{62} & 1.123 & 1.113 & 1.103 & 1.211 & 0.763 & 0.731 & 0.703 & 0.923 \\
\hline & \multicolumn{4}{|c|}{ LL (KA) } & \multicolumn{4}{|c|}{ DLG (KA) } \\
\hline FL & Bus 31 & Bus 32 & Bus 33 & Bus 62 & Bus 31 & Bus 32 & Bus 33 & Bus 62 \\
\hline 31 & 1.080 & 1.069 & 1.058 & 1.028 & 1.152 & 1.130 & 1.111 & 1.077 \\
\hline 32 & 1.029 & 1.063 & 1.052 & 0.981 & 1.097 & 1.137 & 1.116 & 1.030 \\
\hline 33 & 0.982 & 1.013 & 1.046 & 0.937 & 1.046 & 1.082 & 1.123 & 0.986 \\
\hline 62 & 0.980 & 0.970 & 0.961 & 1.058 & 1.037 & 1.021 & 1.008 & 1.133 \\
\hline
\end{tabular}

Increasing number of DG have great support for the increment of fault current level to the system.

\section{Scenario IV Optimal sized and placed DG impact on fault current level}

The selected bus for applying the mitigation technique and fault level analysis with fault level is bus 62 .

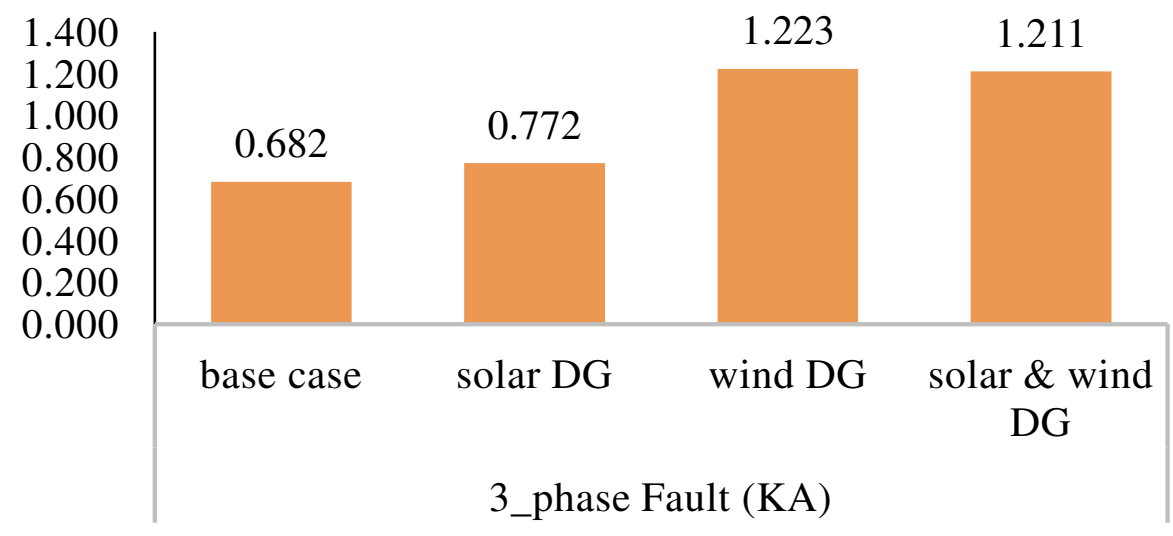

Figure 13 Optimal sized and placed DG impact on fault current level

Fig 16 shows the place where DG sized and placed optimally by PSO and fault level is analyzed to show the need to protection of power system in the integration of DG without replacing the traditional protective devices. 


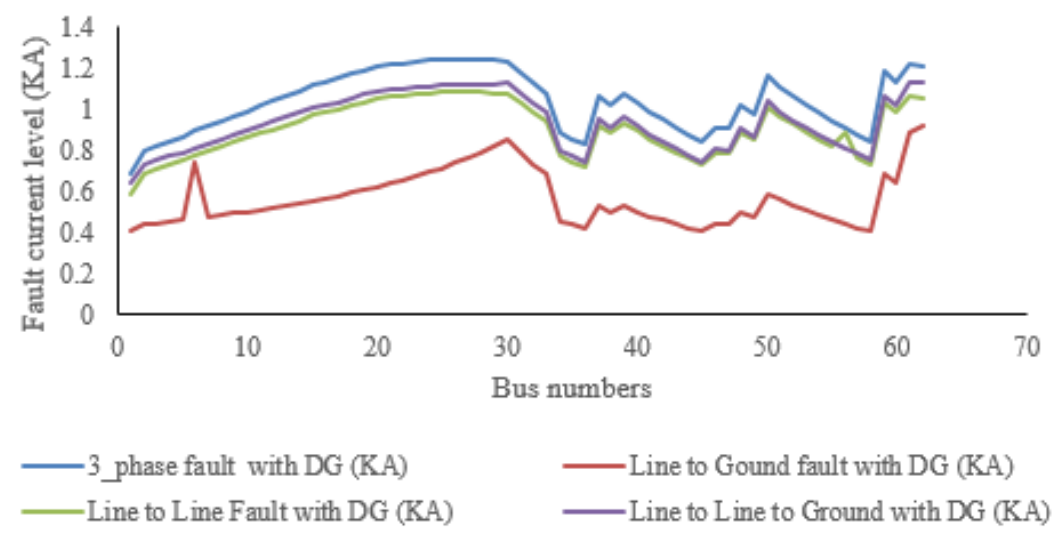

Figure 14 Integration of wind and Solar DG on the DN

Adverse impact of DG was analyzed and it depends on the distance of the fault from the DG (by considering all the buses as fault location), the number of DGs connected to the system and type of DG (which are renewable DGs i.e. solar DG and wind DG).

\section{Conclusion}

This paper covers only two types of DG integration to the combination of solar DG only, wind DG only and solar and wind DG at a time. These combinations are tested with the selected weak buses turn by turn. The fault analysis is done by using ETAP software and the result is taken for the four types of faults which are three phase fault, line to ground fault, line to line fault and double line to ground fault. To show the increment of fault current level due to DG integration to the $\mathrm{DN}$, this paper follows scenarios to give brief illustration to number and size of DG. The base fault current at bus 62 for three phase, line to ground, line to line and line to line to ground are $0.682 \mathrm{KA}, 0.183 \mathrm{KA}, 0.591 \mathrm{KA}$ and $0.610 \mathrm{KA}$ respectively. The fault level magnitude of the system after the integration of solar and wind DG at time for three phase, line to ground, line to line and line to line to ground are $1.211 \mathrm{KA}, 0.923 \mathrm{KA}, 1.058 \mathrm{KA}$ and $1.133 \mathrm{KA}$ respectively.

The protection equipment for power system protection is designed by the analysis of fault with traditional distribution network which are not consider the integration of DG to it. When the DG is integrated to distribution network it changes not only the unidirectional follow of current to bidirectional current but also it increases the amount of fault current to the distribution network at the fault time. This paper confirms designing distribution network without forecasting the future demand of electric power users give the protection equipment additional requirement. As the result shows the base case fault current and the fault current after the integration of DG to the distribution network have great difference value in terms of power system protection. After the integration of the distributed generation the fault current is increased by 
0.529KA for three phase, $0.74 \mathrm{KA}$ for line to ground, $0.467 \mathrm{KA}$ for line to line and $0.523 \mathrm{KA}$ for line to line to ground.

\section{Reference}

[1] T. Gallery, L. Martinez, and D. Klopotan, "Impact of Distributed Generation on Distribution Network Protection,” ESBI Eng. Facil. Manag. ..., vol. 2005, pp. 478-482, 2005.

[2] S. a Soman, "Power System Protection Power System Protection Types of Protection Evolution of Relays Circuit Breaker Summary," System, no. lecture, p. 6.

[3] Dr.Abdallah M.AL.Shehri, "Short Course on Power System Protection-ABB.pdf." .

[4] H. Zayandehroodi, A. Mohamed, H. Shareef, and M. Mohammadjafari, "Impact of distributed generations on power system protection performance," Int. J. Phys. Sci., vol. 6, no. 16, pp. 3999-4007, 2011.

[5] B. Bak-Jensen, M. Browne, R. Calone, R. C. Gonzalez, A. Craib, and G. Donnart, "Protection of Distribution Systems with Distributed Energy Resources," Jt. Work. Gr. B5/C6.26/CIRED, CIGRE, no. March, 2015.

[6] J. Radosavljević, "Fault analysis of distribution networks with DG," pp. 1-14.

[7] D. Sweeting, "Applying IEC 60909, fault current calculations," in IEEE Transactions on Industry Applications, 2012, vol. 48, no. 2, pp. 575-580.

[8] Jorge Santamaria, "Analysis of Power Systems under Fault Conditions," Calif. State Univ. Sacramento, vol. 53, no. 9, pp. 1-93, 2011.

[9] M. Kezunovic, Fundamentals of Power System Protection. 2005.

[10] V. Lackovic, "Introduction to Short Circuit Current Calculations," lecture, no. 877.

[11] U. Shahzad, S. Kahrobaee, and S. Asgarpoor, "Protection of Distributed Generation: Challenges and Solutions," Energy Power Eng., vol. 09, no. 10, pp. 614-653, 2017.

[12] T.-I. Zabava, I. TRIŞTIU, A. Mandiş, and C. Bulac, "Short Circuit Currents Calculations in Distribution Electrical Networks in the Presence of Distributed Generation," vol. 77, pp. 2286-3540, 2015.

[13] S. Boljevic and M. Conlon, "Fault current level issues for urban distribution network with high penetration of distributed generation," 2009 6th Int. Conf. Eur. Energy Mark., pp. 1-6, 2009.

[14] S. C. Reddy, G. Saritha, and N. Vikas, "Effect of distributed generation on distribution systems during faults," in Proceeding of the IEEE International Conference on Green Computing, Communication and Electrical Engineering, ICGCCEE 2014, 2014. 
[15] E. Coster, Distribution grid operation including distributed generation - Impact on grid protection and the consequenses of fault ride-through behavior, no. september. 2010.

[16] E. Coster, J. Myrzik, and W. Kling, "Effect of DG on Distribution Grid Protection," in Distributed Generation, 2010.

[17] S. M. Saad, N. El Naily, J. Wafi, A. Elhaffar, and F. A. Mohamed, "Enhancement of over current coordination for a distribution system connected to a microgrid using unidirectional fault current limiter,” 2018 9th Int. Renew. Energy Congr. IREC 2018, no. Irec, pp. 1-6, 2018.

[18] E. Coster, J. Myrzik, and W. Kling, "Effect of Distributed Generation on Protection of Medium Voltage Cable Grids," Proc. CIRED 19th Int. Conf. Electr. Distrib, no. 0079, pp. 21-24, 2007.

[19] P. Danodia, "Power System Protection," IEEE Power Eng. Rev., vol. 15, no. 9, p. 33, 1995.

[20] Minh-Quan Dang, Possible Issues in Distributed Generation Network Protection Problematika chr'an`en'1 s'1t'1 s decentralizovanou v'yrobou energie. 2014.

[21] A. rasheek. rifaat@jacobs. co. Rasheek Rifaat, P.Eng, IEEE Life Fellow IEEE/IAS/I\&CPSD Protection \& Coordination WG Chair Jacobs Canada, Calgary and IEEE, "Power System Protective Relays: Abstract:," IEEE South. Alberta Sect. PES/IAS Jt. Chapter Tech. Semin. - Novemb. 2016 Prot., no. November, 2016.

[22] E. Engineering, "STUDY OF GENERATION PROTECTION AT GARRI 4 POWER STATION BY B . Sc . ( HON ) in Electrical and Electronics Engineering ( Power system Engineering ),” Thesis Rep., vol. 1, no. 124002, pp. 10-11, 2017.

[23] A. D. Udgave and H. T. Jadhav, "A review on Distribution Network protection with penetration of Distributed Generation,” Proc. 2015 IEEE 9th Int. Conf. Intell. Syst. Control. ISCO 2015, 2015. 


\section{List of abbreviations}

$3 \Phi$

DG

DLG

DN

DS

ETAPS

KA

LG

LL

PSP

SLG
Three phase

Distributed Generation

Double line to ground

Distribution network

Distributed system

Electrical Power System Analysis Software

Kilo Ampere

Line to ground

Line to line

Power system protection

Single line to ground 


\section{Declaration}

\section{Conflict of interest}

I confirmed that there is no A conflict of interest in research.

Ethics approval and consent to participate

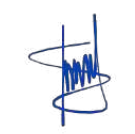

\section{- Consent for publication}

I a need to the publication of these paper

\section{- Availability of supporting data}

Not applicable

\section{- Competing interests}

There is no opposing interest of these paper

\section{- Funding}

No funding

\section{- Authors' contributions}

I the author have done the paper which are the basic analysis, documenting, data collection, software analysis and submitting to the publisher.

\section{- Acknowledgements}

Thank you considering my paper to publications. 